\title{
Assessing the Impacts of Ageing and Natural Resource Extraction on Carbon Emissions: A proposed Policy Framework for European Economies
}

\author{
Daniel Balsalobre-Lorente ${ }^{1}$ \\ Department of Political Economy and Public Finance, \\ University of Castilla La Mancha, Spain. \\ Email: Daniel.Balsalobre@uclm.es \\ Avik Sinha \\ Centre for Excellence in Sustainable Development, \\ Goa Institute of Management, India. \\ Email: f11aviks@iimidr.ac.in
}

\author{
Oana M. Driha \\ Department of Applied Economics, International Economy Institute, \\ Institute of Tourism Research, University of Alicante, Spain. \\ Email: oana.driha@ua.es \\ Muhammad Shujaat Mubarik \\ Faculty of Business Administration \& Social Sciences, \\ Mohammad Ali Jinnah University, Karachi, Pakistan. \\ Email: shujaat.mubarak@jinnah.edu
}

\begin{abstract}
Given the rise in ageing population and rising globalization, the European nations are facing difficulties in encountering the climate action and ascertaining energy security. For diffusing the energy innovations and curtailing natural resource extraction, with an objective of reducing carbon emissions, the existing policy framework in these nations might need a reorientation, and there comes the role of the study. This study recommends a policy framework for exploring the effect of natural resource extraction and age dependence on carbon emissions in top-5 European countries (EU-5) for the period of 1990-2017. By applying the Second Generation Panel Modeling approach, the empirical results indicate that the associations of carbon emissions with natural resource extraction, globalization index, and economic growth and ageing population follow an inverted U-shaped relationship, in keeping with the framework of Environmental Kuznets Curve (EKC) hypothesis. Based on the findings of the study, a multipronged Sustainable Development Goal (SDG) framework has been designed, and through this framework, SDG 7, SDG 13, and thereafter SDG 8 have been evaluated. While these three SDGs are the central focus of the study, the SDG framework has also suggested a way to evaluate several tangential SDGs.
\end{abstract}

Keynotes: Natural Resources; Globalization; Energy Innovation; Ageing; Carbon Emissions

\footnotetext{
${ }^{1}$ Corresponding author
} 


\section{Introduction}

The rise in industrialization is causing the economic growth trajectory to be taking a departure from being sustainable, and this issue has been the primary focus of the Sustainable Development Goals (SDG) 2018 report (United Nations 2018). According to this report, both the developed and developing economies face difficulties in fulfilling the purposes of SDG 13, i.e., climate action, and one of the primary reasons behind this predicament has been identified as the industry-led economic growth pattern. While accomplishing economic growth, crossborder traversing of resources has been alleviated progressively, and it has been conceivable by means of globalization. The direct influence of globalization on production procedures via the transaction of products and services has environmental consequences. Moreover, treading along the fossil fuel-based growth trajectory makes it problematic for nations to realize the purposes of SDG 7, i.e., affordable and clean energy. Further, this purpose's defiance might, in due course, persuade the departure from accomplishing the goals of SDG 8, i.e., decent work and economic growth. In this context, the upswing in globalization might carry a severe hazard to the basis of sustainable development in developed economies.

Given the background of globalization, energy utilization patterns, and natural resource extraction, European countries need special mention. Energy and natural resources play an apex role in the industrial development of these nations. While catalyzing the echelon of economic growth, they also worsen environmental quality in these nations. The recent Eurostat Report (2019) suggests that these economies are facing difficulties in achieving the purposes of SDG 13, and a major reason is attributed to the status of energy innovation and responsible consumption of natural resources. While they have made moderate progressions in renewable energy implementation and reduced inequalities, ongoing energy innovations might hinder the way of achieving the SDGs by 2030.

Since the European Union (EU) ratified the Kyoto agreements, energy programs have established measures for strengthening environmental and energy regulations, intending to reduce carbon emissions by controlling energy consumption (EU, 2014). These initiatives are traced back to the demographic transformations and globalization, which appeared in the European countries during the mid-twentieth century. These transformations are based on the assumption of modern living standards, environmental actions, and energy-saving measures to reduce emissions in the 5 largest European countries $^{2}$ (EU-5) (UNDP 2016). From an economic perspective, a rise in the ageing population might create a shortage of labour supply. Whereas from an environmental perspective, building second homes for the ageing population, mobilizing them, and changes in their household pattern might reduce the environmental quality through ageing and cohort effects. A baseline report by COWI (2008) focused on these aspects, and the same was reinforced in the European Commission report (2014).

Moreover, the recent ageing report by European Commission (2018) states that the long term and healthcare expenditures are expected to grow annually by more than 2 per cent, which might significantly impact the public spending on infrastructural and industrial development and other fiscal benefits. This shrinkage in public spendings might have a significant impact on the job creation scenario in the EU-5 countries, diluting the purposes of SDG 8 .

\footnotetext{
2 The 5 largest economies in the EU during the period analysed (1990-2017) were Germany, France, United Kingdom, Italy and Spain. It is worth mentioning that these countries are also among the most dynamic ones in terms of renewable energy and energy innovation. Moreover, the EU is facing an increase of elderly population (over 65 years old) from $13 \%$ to over $19 \%$ while the global range is going from $6 \%$ to $8 \%$ and, among EU5, only UK registered a slightly lower elderly population (see OECD database).
} 
Simultaneously, relocation and mobility of the ageing citizens will add directly to the transportinduced emissions. Likewise, household pattern deviations might add to energy-induced and space heating emissions through structural changes in power utilization patterns. In such a situation, lacking in the front of energy innovations might prove to be dear for the EU-5 nations, as these nations are already encountering rising emissions. However, following the recent Eurostat report (2019), these measures might require reinvestigation so that a policy mainstreaming can be suggested for these nations to attain sustainable development.

In a nutshell, the above discussion substantiates the need for a comprehensive policy framework for the EU 5 countries, which can play an instrumental role in attaining the SDGs objectives by 2030. Against this backdrop, the present study aims to analyze the impact of natural resource extraction, globalization, economic growth, energy consumption, energy innovations, and the ageing population on carbon emissions in the EU-5 nations over the period of 1990-2017. As the EU-5 countries can be considered the leading developed economies, laying out an SDG framework for these nations is expected to benefit other developed economies in policy recalibration. Consideration of these parameters within a single policy agenda might help design a comprehensive policy framework for addressing the objectives of SDG 7 and SDG 13, and thereafter SDG 8. To the best of our knowledge, there is a void in the literature on developing and adopting a SDG-oriented policy-level approach to address environmental degradation. Bridging this gap is the major contribution of the present study.

Now, evaluating the influence of policy parameters considering economic spillovers and structural similarities necessitates the analysis to be carried out in the Second-Generation approach. Any first-generation methodological approach may not capture the cross-sectional heterogeneity arising from the economic spillovers and structural similarities. Therefore, in this pursuit, the cross-sectional autoregressive distributed lag (CS-ARDL) method is employed in this study. This method can control for the structural similarities among the nations while demonstrating the impacts of explanatory policy parameters to differ in terms of level, mode, and response period. Because of these advantages, this study has employed CS-ARDL approach rather than the traditional ARDL approach (Chudik and Pesaran, 2015; Everaert and De Groote, 2016).

Further, choosing a suitable theoretical framework for analyzing this association is required, as the analysis will be carried out for capturing the evolutionary impact on the target policy variable. Hence, the Environmental Kuznets Curve (EKC) hypothesis has been chosen due to its ability to capture the evolutionary impact within a panel data framework (Dinda, 2004; Shahbaz and Sinha, 2019). Hence, the anticipated model outcomes might recommend near-exact consequences for this context, which can be imitated in the case of other developed economies. This theoretical schema could be considered as one of the analytical contributions of the study.

The rest of the paper is organized as follows: Section-II presents the existing literature review and the theoretical considerations following the previous studies. Section-III offers the details of the empirical model, data description, and methodology applied to validate our initial hypotheses. Section-IV discusses the econometric results, and Section-V presents the discussion of policy implications. Finally, in Section-VI, the conclusion is presented.

\section{Literature Review}

\subsection{Energy and Environmental Degradation}


The literature of energy and environmental economics has widely discussed the EKC hypothesis (Grossman and Krueger 1991, Panayotou 1993, Sinha et al. 2019). This hypothesis infers that economic growth affects environmental quality via three channels: scale, technique, and composition effects (Torras and Boyce 1998, Shahbaz et al. 2015, Alvarez et al. 2017). The EKC hypothesis also considers the role of additional factors such as natural resources, globalization, and energy innovations or demographic changes, i.e., the ageing population (Dooley 1998). Current studies have considered that energy innovation is the main key driver behind the decline in global warming and assurance of sustainable economic growth (Balsalobre and Álvarez 2016, Álvarez et al. 2017, Chen et al. 2021). Torras and Boyce (1998) demonstrated that energy innovations improve environmental quality, thereby attributing technical effect as the central feature in plummeting ambient pollution (Aghion et al. 2014). Furthermore, recent literature establishes that low-carbon technologies delay the scale effect and the appearance of technical obsolescence (Álvarez et al. 2017; Destek and Sinha 2020). A detailed review of the studies analyzing this association has been carried out by Shahbaz and Sinha (2019).

\subsection{Natural Resources and Environmental Degradation}

Several empirical evidence demonstrates that the presence of abundant natural resources plays a crucial role in economic systems. Auty (2001) observed that the growth of per capita income is slower in countries with abundant natural resources. However, Bravo-Ortega and De Gregorio (2005) found that natural resources positively affect income, but negatively affect its growth rate. Several studies have validated the "natural resource curse hypothesis" (Shahbaz et al. 2019b). Following the theory mentioned above, Brunnschweiler and Bulte (2008) stated a difference between natural resource dependence and natural resource abundance. They concluded that natural resources dependence did not affect economic growth, but natural resources' abundant availability enhances economic growth. In line with the relationship between the environment and natural resources, Balsalobre et al. (2018) demonstrated that natural resource abundance reduces ambient carbon emissions in the European countries. The results confirmed that resource-abundant nations imposed import-substitution for fossil fuel and energy dependence and preferred to utilize energy-efficient technology to maintain economic development and living standards. However, the counter-evidence has been produced by Danish et al. (2019) for the BRICS nations.

\subsection{Globalization and Environmental Degradation}

For increasing globalization, a continuous and multidimensional integration process is promoted to integrate the economic, social, and political relations across the globe. The process of globalization is anticipated to have a positive effect on economic development (Dreher, 2006). The study of Dollar and Kraay (2004) in this regard found a positive relationship between globalization (employing trade flows and FDI) and economic growth. Likewise, additional empirical evidence postulates that globalization could be articulated through innovation. Kahuthu (2010) examined the income- $\mathrm{CO}_{2}$ emissions association moderated by globalization and found a direct association between economic integration and environmental quality. It implies that globalization allows administrations to adjust trade policies by reducing trade barriers for importing energy-efficient technologies.

In the relationship between globalization and environmental degradation, Shahbaz et al. (2013) found that trade openness (globalization) deteriorates environmental quality. 
Similarly, in another study, Shahbaz et al. (2015) further examined the globalization- $\mathrm{CO}_{2}$ emissions association for the Indian economy. The empirical evidence of the study revealed that globalization was pernicious to environmental quality. This empirical evidence has been supported by studies carried out in diverse contexts (e.g., Shahbaz et al. 2017a; Shahbaz et al., 2018) also support this fact. For example, Shahbaz et al. (2018) demonstrate that globalization catalyzes FDI, which further can lead toward the use of cheaper and dirtier manufacturing techniques to capitalize on natural resources for making higher profits. It implies that the worsening of environmental quality can be owing to the weak enforcement of ecological directives. Nevertheless, Shahbaz et al. (2017b) found globalization helpful for Australia's environmental quality and reported that globalization could have an ancillary impact on environmental administration policies and resource distribution.

\subsection{Ageing and Environmental Degradation}

Lastly, considering the impact of ageing over environmental degradation, several studies have explored the connection between ageing and carbon emissions (Farzin and Bond 2006). York et al. (2003) and Shi (2003) stated that economies with a high percentage of working people could suffer more carbon emissions. Likewise, Fan et al. (2006) confirmed that the workingage population's proportion correlates positively with carbon emissions in low-income countries but negatively with high-income countries. Further, Dalton et al. (2008) found that older people use less private transport, which reduces the use of cars and resources, thereby reducing pollution. Hassan and Salim (2015) concluded that in the long run, a one per cent increase in the share of aged-population results in lowering per capita $\mathrm{CO}_{2}$ emissions by 1.55 per cent. However, O'Neill et al. (2010) claimed an indirect effect of demographic structure on $\mathrm{CO}_{2}$ emissions, which works via labour market dynamics. In this study, the ageing-population is related to the lower labour participation rate, which slows down economic growth, reducing carbon emissions.

On the contrary, other studies have provided evidence about the negative impact of the ageing population on environmental quality. For instance, Farzin and Bond (2006) found that societies with a high share of age dependence experience increased carbon emissions. Similarly, Menz and Welsch (2010) found that senior people consume more energy-intensive goods, aggravating carbon emissions. In another study, Menz and Welsch (2012) found that the correlation between the ageing population and carbon emissions depends on the country's position in the development process. Furthermore, based on some empirical evidence, the impact of the ageing population is related to age-specific energy demand in different consumption and production sectors. In this sense, aged people would probably be opposed to stricter environmental regulation (Heijdra et al. 2006). On the link between age-dependence and environmental preferences, Thalmann (2004) indicated that the inclination to spend for healthier ecological quality, i.e., green taxes, significantly decreases with age. The study's outcome implies that though the senior people would bear the costs instantaneously, they will not benefit from higher environmental quality in the future, which gradually diminishes environmental awareness. Liddle and Lung (2010) found people have a comparatively higher energy-intensive lifestyle in early adulthood and the "retirement age", and have a relatively less energy-intensive lifestyle during the "middle age" (35-64). Furthermore, Liddle (2011) found the existence of a U-shaped relationship between the age structure and residential electricity consumption and concluded that the youngest and oldest (20-34 and 70 and older) have positive coefficients, whereas the middle cohorts (35-49 and 50-69) have negative coefficients. The result was indicative of an indirect increase in carbon emissions among the youngest and oldest populations through energy consumption. 


\subsection{Research gap}

This brief review of the literature suggests that the parameters taken up in the studies might have a possible impact on environmental degradation. However, these studies are silent about the definitiveness of this association's associative directionality, as it can be seen that the directions vary according to the level of development in the sample nations. While the parameters could be instrumental in designing policies for ascertaining sustainable development, their roles have been largely undermined in the literature. Moreover, the applicability of the EKC hypothesis as an analytical framework for policymaking has also been unaddressed in the literature. This gap is addressed by considering ageing in the multipronged SDG framework suggested in this study.

\section{Empirical framework}

\subsection{Theoretical rationale}

High level of economic growth characterizes the EU-5 nations and this growth is achieved by significant consumption of fossil fuels and complemented by the smooth cross-border movement of resources via globalization. Alongside these aspects, the abundance of natural resources gave these nations leverage to accelerate economic growth. With the rise in economic growth in these nations, the standard of living started to improve, and with the graduation of time, the average life span of the citizens began to rise.

However, this fossil fuel-based growth pattern in these nations was exerting negative environmental externality in carbon emissions. Fueled by globalization, demand for energy was rising in the industrial sector, and prevailing energy innovations were not adequate to reduce this level of emissions. Moreover, relocation and rehabilitation of ageing citizens caused a change in the household energy consumption pattern, which also started adding to the carbon emissions. Driven by these rising ecological predicaments, in 1990, the European Union conceived the European Environment Agency's idea, which was later formed in 1993. It was the year 1990 when the European Commission started looking into environmental degradation issues, in association with the parliament (European Commission 1990). Since 1990, environmental regulations in the European Union have begun to be more stringent so that the issues of rising carbon emissions can be controlled. Hence, 1990 might be considered as a starting point of this study. Given this regulatory intervention, a shock to the major economic indicators is expected to bring forth a reversal in the prevailing carbon emissions pattern.

In this contextual backdrop, it is necessary to analyze the impact of these economic indicators on carbon emissions following a theoretical framework, which will allow the evolutionary impact over a specified temporal frame. Henceforward, this study has embarked on the EKC hypothesis framework. This framework can be mathematically explained as the following:

$$
E D_{i t}=a_{0}+a_{1} E I_{i t}+a_{2} E I_{i t}^{2}+a_{3} X_{i t}+\epsilon_{i t}
$$

Here, ED symbolizes environmental degradation, EI is the set of major economic indicators, which can have a possible impact on $\mathrm{ED}$, and $\mathrm{X}$ is the set of other covariates to have a possible impact on ED. ' $i$ ' and ' $t$ ' denote the sample countries and years, for which the analysis is carried out. In this context, EI and X can be defined as the following: 


$$
\begin{aligned}
& E I=\{Y, G, A, N R\} \\
& X=\{E, R D\}
\end{aligned}
$$

Here, Y denotes economic growth, $\mathrm{G}$ denotes globalization, A denotes ageing population, NR denotes natural resources, E denotes fossil fuel energy consumption, and RD denotes research and development towards energy innovation. As the respective evolutionary impacts of $\mathrm{E}$ and $\mathrm{RD}$ are expected to be positive and negative, they are considered as exogenous to the EKC framework. On the other hand, the evolutionary impacts of Y, G, A, and NR are unknown, and by means of the analysis, this study aims to discover that. According to the generally accepted form of EKC hypothesis, the necessary condition is $a_{1}>0$ and $a_{2}<0$, i.e. the associative directionality will take an inverted U-shaped form. This form of association might give a possible indication of the evolutionary impact of the model parameters on environmental degradation.

With the rise in economic growth, environmental degradation starts to rise. After arriving at a threshold level, the economic growth pattern catalyzes the environmental degradation to start diminishing. However, this impact does not arise automatically. Extraction of natural resources rises with economic growth, and consequential environmental degradation sets in as countries start investing in energy innovations, gradual improvement in energy efficiency starts, which slows down the demand for natural resources. Henceforth, the negative environmental externality exerted by the process of natural resource consumption starts coming down after reaching a peak. During this period, the globalization process might allow technology transfer between the nations, and therefore, gradually, countries can develop their innovation capability, following a rise in the standard of living and educational attainment. Until this process is executed, globalization continues to exert negative environmental externality by accelerating the production processes. Once the capacity to innovate is achieved, energy innovations restrict the importing of outdated and/or polluting technologies. From this point onward, the negative environmental externality exerted by globalization starts reducing. Shahbaz et al. (2019a) have discussed this issue in detail.

When the innovations are at the nascent stage, relocation and rehabilitation of ageing population start exerting negative environmental externality through the changes in energy consumption patterns at the household level. Moreover, the increase in mobility and transport volume adds to the rising environmental degradation. With incremental energy innovations, the negative environmental externalities start getting internalized. Moreover, continuous efforts towards enhancing the level of awareness among the aged population also reduce the level of environmental degradation.

By far, following the premise of the EKC hypothesis, the discussion suggests that the possible evolutionary impacts of the economic indicators on environmental degradation might follow an inverted U-shaped form. Simultaneously, fossil fuel energy consumption and research and development towards energy innovation might have positive and negative impacts on environmental degradation, respectively. Based on this theoretical proposition, this study intends to analyze this association for the EU-5 nations from 1990 to 2017. The empirical models utilized in the study are explained in the next section.

\subsection{Data and empirical model}


This study uses annual data for the period of 1990-2017 for the top-5 European countries (France, Germany, Italy, Spain, and the UK). The data on real GDP (constant 2010 US\$), $\mathrm{CO}_{2}$ emissions (metric tons), energy consumption ( $\mathrm{kg}$ of oil equivalent), natural resources as the share of GDP (constant 2010 US\$), an ageing population (share of population greater than 65 years of age) was gathered from World Development Indicators (World Bank, 2018). Moreover, the data on globalization and energy innovations are taken from KOF database (Gygli et al., 2019) and the OECD database. The description of all the variables used in the empirical model is presented in Table-1. Except for globalization, all the model parameters are converted into per capita terms.

\section{<Insert Table 1 here> \\ $<$ Insert Table 2 here>}

Table-2 shows the descriptive statistics and correlation matrix. It can be noted that the correlation between economic growth and carbon emissions is positive. Direct associative presence is seen for energy consumption and carbon emissions, but it has a negative relationship with economic growth. Globalization is negatively correlated with carbon emissions, but natural resources are positively related to carbon emissions. Inverse associative presence is seen between $\mathrm{CO}_{2}$ emissions and energy innovations and ageing, respectively. The summary of the statistics demonstrated that the variables do not show central tendencies, with longer tails. Owing to this, the regression estimates might be biased. The results of the JarqueBera test result also succumb to this claim.

In continuation of the theoretical framework, the empirical model of the study is as per the following:

$$
\begin{aligned}
C_{i t}= & \beta_{0}+\beta_{1} N R_{i t}+\beta_{2} N R_{i t}^{2}+\beta_{3} G_{i t}+\beta_{4} Y_{i t}+\beta_{5} R D(-2)_{i t}+\beta_{7} A_{i t}+\beta_{9} E_{i t}+\epsilon_{i t} \\
C_{i t}= & \beta_{0}+\beta_{1} N R_{i t}+\beta_{2} N R_{i t}^{2}+\beta_{3} G_{i t}+\beta_{4} G_{i t}^{2}+\beta_{5} Y_{i t}+\beta_{6} R D(-2)_{i t}+\beta_{7} A_{i t}+\beta_{8} E_{i t}+\epsilon_{i t} \\
C_{i t}= & \beta_{0}+\beta_{1} N R_{i t}+\beta_{2} N R_{i t}^{2}+\beta_{3} G_{i t}+\beta_{4} G_{i t}^{2}+\beta_{5} Y_{i t}+\beta_{6} Y_{i t}^{2}+\beta_{7} R D(-2)_{i t}+\beta_{8} A_{i t}+ \\
& \beta_{9} E_{i t}+\epsilon_{i t} \\
C_{i t}= & \beta_{0}+\beta_{1} N R_{i t}+\beta_{2} N R_{i t}^{2}+\beta_{3} G_{i t}+\beta_{4} G_{i t}^{2}+\beta_{5} Y_{i t}+\beta_{6} Y_{i t}^{2}+\beta_{7} R D(-2)_{i t}+\beta_{8} A_{i t}+ \\
& \beta_{9} A_{i t}^{2}+\beta_{10} E_{i t}+\epsilon_{i t}
\end{aligned}
$$

where, $\mathrm{C}, \mathrm{Y}, \mathrm{G}, \mathrm{NR}, \mathrm{RD}, \mathrm{A}$, and $\mathrm{E}$ respectively represent per capita $\mathrm{CO}_{2}$ emissions, real GDP per capita, real natural resource revenues per capita, globalization, energy innovations, ageing population, and per capita fossil fuel energy consumption. $\mathrm{RD}(-2)_{\text {it }}$ is delayed by two periods in accordance with the previous literature when energy innovation processes present the highest impact on emissions (Cantos and Balsalobre 2013, Álvarez et al. 2017, Fernández et al. 2018).

On the methodological front, the present study has adopted the Second-Generation approach. There is a specific reason for adopting this approach. As the EU-5 nations are associated with each other via a unified policy regime, therefore, the economic spillovers will associate them at the structural level, which might appear as cross-sectional dependence. Consideration of this aspect not only gives a logical underpinning for the methodological design but also, this approach complies with the policy-level contribution of the study. The methodological schema is the following: First, second-generation unit root tests are used for checking the stationarity property of the variables. Upon checking the stationarity property of the model parameters, we have checked the long-run association among them by employing 
the second-generation cointegration method. Upon confirming the presence of cointegrating association among the variables, we have estimated long-run coefficients using a crosssectional autoregressive distributed lag (CS-ARDL) test, and lastly, the causality associations among the variables have been estimated using Dumitrescu-Hurlin Panel causality test. A detailed description of all these tests is added in the Supplementary Materials for understanding and replication purposes.

As the squared term of the variables is used, it is probable that the model might be suffering from multicollinearity. Before starting the analysis, the multicollinearity issue has been checked using the Variance Inflation Factor (VIF), and the results are reported in Appendix 1. To handle the issue, all the variables were orthogonally transformed, and it solved the issue of multicollinearity (see Appendix 1). Subsequent to this step, the entire empirical exercise has been carried out.

\section{Discussion of results}

For identifying a possible long-run relationship among the variables, the variables should be first-order integrated, and it was determined using the panel unit root test. However, before carrying out the unit root tests, it is necessary to check the applicability of the tests, and this has been accomplished through Chudik and Pesaran (2015) weak cross-sectional dependence test. The test outcome reported in Table 3 denotes that the variables are cross-sectional dependent, and it sanctions the applicability of the Second-Generation panel unit root tests. Table-3 outlines outcomes of cross-sectional Im-Pesaran-Shin (CIPS) and cross-sectionally augmented Dickey and Fuller (CADF) panel unit root tests, and the results suggest that the variables are integrated to first order, i.e., I(1).

\section{$<$ Insert Table 3 here>}

Considering the integration order of the variables, we examined the possibilities of long-run association among the model parameters. For this purpose, Westerlund and Edgerton (2008) cointegration test were applied as it accommodates the cross-sectional dependence in the data, and the outcomes presented in Table-4 indicate significant long-run association among the model parameters. This empirical outcome validates the presence of cointegration among the model parameters.

\section{$<$ Insert Table 4 here>}

The presence of cointegration among the variables led to examining the long-run impact of natural resources, economic growth, globalization, energy innovations, ageing, and energy use on carbon emissions through the application of the CS-ARDL. The empirical outcomes are described in Table-5 and Figure-1, and the diagnostic statistics (see Appendix 2) demonstrate that the models are free from heteroskedasticity, serial correlation, normality, and omitted variable bias. The CS-ARDL results depicted several insights regarding the impacts of these model parameters. Those insights are described sequentially.

\section{$<$ Insert Figure 1 here>}

The analysis starts with analyzing the impact of natural resources on carbon emissions. The temporally progressive impact of natural resources on carbon emissions is found to be following an inverted U-shaped form (Figure 2). This segment of results apparently signifies 
that with the progression of time, the diminishing dependence on natural resources might lead to reduced carbon emissions. However, the turnaround points of this association for Eq. 4 to 7 are beyond the sample range, and this gives an indication regarding the unsustainable nature of resource consumption in the EU-5 nations. The dependence of industrial and transport sectors on fossil fuel-based solutions exert negative environmental externality, as indicated by Balsalobre et al. (2018). This issue has also been outlined by the European Environmental Agency (2020) while describing the impact and possible future of the $7^{\text {th }}$ Environment Action Programme. This impact of natural resources becomes clearer when the impacts of energy innovation and energy use on carbon emissions are analyzed together. As expected, the impact of energy innovation is negative across four estimation equations (see Fernández et al. 2018), whereas the impact of energy use is negative. However, when the impact sizes are analyzed, then it can be seen that the impact of energy use is more than 50 times higher than the impact of energy innovation. It demonstrates that energy innovation in EU-5 nations is still at a nascent stage. The negative environmental externality exerted by fossil fuel-based energy consumption could not be lessened. This finding complements the impact of natural resources by demonstrating the issue of resource-inefficiency being faced by these nations. This issue has also been identified by UNEP (2020) while describing UNEP's undertakings on resource efficiency in the EU.

\section{$<$ Insert Figure 2 here>}

On the other hand, the evolutionary impact of economic growth on carbon emissions is found to be inverted U-shaped, thereby validating the EKC hypothesis (Figure 3). This segment of results apparently signifies that economic growth patterns might lead to reduced carbon emissions with time. Now, this association's turnaround points for Eq. 6 and 7 are within the sample range, which indicates the economic growth pattern prevailing in the EU-5 nations to be ecologically sustainable. The results also demonstrate a reduction in the turnaround points of this association. One of the major reasons behind the reduction in turnaround points can be attributed to the improvement in energy efficiency, which is a result of the gradual improvements in the energy innovation scenario. In this regard, Horizon 2020 programme needs a special mention, which has been focused on improving the environmental quality through energy innovations (European Commission, 2020a). When this segment of the outcome is analyzed in parallel with globalization's impact, another possible logical explanation of this phenomenon can be suggested. The impact of globalization has been found to be negative, whereas the evolutionary impact of globalization depicted through the quadratic form is inverted U-shaped (Figure 4). This segment of the results signifies that the globalization pattern is exerting a positive environmental externality in the EU-5 nations. The turnaround points of this association are found to be rising within the sample range, which signifies the need for higher trade with nations might result in the betterment of environmental quality. With the evolution of globalization, green technology transfer among nations rises, while the trade of polluting resources declines. It has a direct positive impact on both the economic growth pattern and environmental quality. The EU Strategy "Europe 2020" is focused on this objective, which entails integrating the ecological facets in strengthening the trade relations and more trade liberalization (European Commission, 2020b). The impact on environmental quality is achieved by bringing forth gradual resource efficiency in the economic system, and this has started improving environmental quality. This segment of the finding falls in line with the findings by Shahbaz et al. (2017a, b). On the other hand, globalization helps the economic structure transform from secondary to tertiary, and this transition helps the economic growth pattern exert less pressure on environmental quality. This segment of the finding adheres to Tisdell's (2001) findings and Corpataux et al. (2009). 
$<$ Insert Figure 3 here>

$<$ Insert Figure 4 here>

Lastly, the impact of ageing on carbon emissions is analyzed. It can be seen that the ageing influences the rise in carbon emissions, and it is consistent from Eq. 4 to 6. However, with the quadratic specification in Eq. 7, the evolutionary impact of ageing on carbon emissions has been found to be inverted U-shaped (Figure 5). It signifies that ageing can impact the carbon emission until a point beyond which the negative environmental externality exerted by ageing starts diminishing. It signifies that the changes in demographic transformations, which occurred in the EU-5 during the last few decades, have led to increase in emissions. However, following the findings of Hamza and Gilroy (2011), it can be mentioned that efforts to diminish carbon emissions might be impeded by the consumption-transformation resulting from a distinct ageing section. Moreover, the gradual rise in energy efficiency arising out of energy innovations might contribute to improvements in fuel efficiency in transport and household consumption. Policy decisions made in 2014 by the European Commission (2014) on promoting the "silver economy" and maintaining intergenerational partnerships by balancing vocational commitments and care provision might have started demonstrating an impact on the energy consumption pattern of the aged citizens, as mere environmental compliance might not prove to be viable (see Heijdra et al. 2006).

\section{$<$ Insert Figure 5 here> \\ $<$ Insert Table 5 here>}

Table-6 exhibits the results of pairwise Dumitrescu and Hurlin (2012) panel causality test. We found bidirectional causality among the following variables: emissions and economic growth, ageing and economic growth, globalization and carbon emissions ( $\mathrm{H} \leftrightarrow \mathrm{C}, \mathrm{A} \leftrightarrow \mathrm{C}$; $\mathrm{NR} \leftrightarrow \mathrm{Y} ; \mathrm{A} \leftrightarrow \mathrm{Y} ; \mathrm{A} \leftrightarrow \mathrm{G} A \leftrightarrow \mathrm{RD} N R \leftrightarrow \mathrm{G} ; \mathrm{RD} \leftrightarrow \mathrm{G})$. The bidirectional associations signify certain insights, which might be necessary from the perspective of policy design. The bidirectional associations between (a) carbon emissions and income and (b) carbon emissions and ageing depict that the rising carbon emissions in the EU-5 countries can harm the economic growth pattern by causing harm to the hygienic state of the labour force, a glimpse of which can be seen by the impact of carbon emissions on ageing. This impact might pose a threat not only to the potential of 'silver economy' but also to the human capital of the nation. On the other hand, the bidirectional associations between (a) natural resource abundance and economic growth and (b) ageing and economic growth depict that the economic growth pattern prevailing in the EU-5 countries might be posing a threat to the basis of growth itself. While natural resource abundance is having an impact on economic growth, the economic growth pattern is creating a demand for natural resources. This causality might be attributed as a reason behind the environmental concerns in these nations. On the other hand, the rise in economic growth might indicate betterment in the livelihood pattern, thereby promoting 'silver economy' through ageing. Now, ageing might enhance industrial demand by bringing transformations in the household pattern, and that can enhance the scope of globalization. However, the negative environmental externalities caused by ageing might require the EU-5 countries to boost the energy innovations, which can be driven by the pace of globalization. At the same time, the rise in industrialization, driven by globalization, is also responsible for the consumption of natural resources.

Along with these, unidirectional causal associations run from: (a) economic growth to energy innovation and energy use $(\mathrm{Y} \rightarrow \mathrm{RD}$; $\mathrm{Y} \rightarrow \mathrm{E})$, (b) natural resources abundance to $\mathrm{CO}_{2}$ 
emissions and energy innovation $(\mathrm{NR} \rightarrow \mathrm{C}$; NR $\rightarrow \mathrm{RD}$ ), (c) carbon emissions to energy innovations and energy use $(\mathrm{C} \rightarrow \mathrm{RD} ; \mathrm{C} \rightarrow \mathrm{E})$, (d) ageing to natural resources abundance $(\mathrm{A} \rightarrow \mathrm{NR})$, and (e) energy use to natural resources abundance, ageing, and innovation $(\mathrm{E} \rightarrow \mathrm{NR}$; $\mathrm{E} \rightarrow \mathrm{G} ; \mathrm{E} \rightarrow \mathrm{A} ; \mathrm{E} \rightarrow \mathrm{RD})$. To summarize, these associations demonstrate specific insights regarding the economic growth pattern in these nations. With a rise in industrialization, energy use rises, and it adds to industrial production, which sets the pace for globalization. However, negative environmental externalities caused by energy use through the consumption of natural resources compel the policymakers to promote energy innovation. Moreover, on the one hand, this energy use also adds to the betterment in livelihood standards, which is reflected in ageing, and on the other hand, it indirectly adds to carbon emissions, rise in which pushes the policymakers to promote energy innovation, so that the energy use pattern can be altered.

$<$ Insert Table 6 here $>$

\section{Implications for sustainable development}

To implement the SDGs, results obtained in this study might prove to be significant for the EU-5 nations. These nations are characterized by high economic growth and high consumption of fossil fuel. Hence, a policy-revamp is required in these nations to encapsulate the broad aspects of sustainable development. Our findings can shed light on this aspect.

At the very outset in the developmental trajectory, economic growth patterns and globalization seem to have a negative effect on environmental quality because the attainment of economic growth is the main priority of the policymakers during this phase. In the pursuit of higher economic growth, nations try to attract investments even at the cost of the environment. With time and growth in income, the industrial structure has shifted from the heavy manufacturing industry to the service industry. Furthermore, owing to the growing industrial demand, globalization brings forth cleaner technologies in the economy. The jobs created in this process might focus on uplifting the living standard of the population, and the young generation needs to be included in the decision-making process to make it possible. This is important from the perspective of maintaining intergenerational equity, which is the foundation of sustainable development.

While talking about sustainable development, it is important to discuss SDGs' different objectives that can be addressed through the results obtained in our study. In this pursuit, we need to address these nations' energy policies so that economic growth is sustainable and inclusive (Roy and Singh, 2017; Roy et al., 2018). By addressing the energy policies, the issues of environmental degradation, affordable and clean energy, sustainable cities and communities, responsible consumption and protection, and good health and well-being can be handled effectively. Therefore, to replace the existing fossil fuel-based solutions, nations need to introduce renewable energy solutions through technological development, achievable through endogenous and exogenous research and development (Sinha et al. 2017, 2018, Zafar et al. 2018). The exogenous way of achieving technological development can be possible through the international technology trade, which is largely driven by globalization. However, to sustain economic growth, endogenous technological development is necessary. Thus, the implementation of renewable energy solutions across the nations might help create new jobs for the younger generation. In this way, the awareness regarding the use of environmentfriendly renewable energy solutions can be spread, which might not be possible with the older generation's people, as they are reluctant to shift their preferences. Therefore, the inclusion of new generation employees in the decision-making process might help the nations develop 
people-public-private partnerships as the building blocks of a sustainable development process (Zafar et al. 2020). Thus, the objectives of the following SDGs can be addressed: (a) Goal 13: accomplishment against the climatic shift, (b) Goal 7: low-cost green energy, (c) Goal 11: resilient community building, and (d) Goal 8: decent economic growth. These objectives can be achieved by encouraging people-public-private partnerships to implement endogenous renewable energy solutions and create green jobs for the young generation in the nations.

However, it is also necessary to remember that the pool of natural resources can act as a catalyst for bringing down environmental issues. During the initial phase of development, industrial growth is generally obtained by exporting or depleting the pool of natural resources. However, with the rise in income and environmental awareness among the citizens, a pool of natural resources starts increasing, which will help gradually develop a new habitat for various species of flora and fauna (Sharif et al., $2020 \mathrm{a}, \mathrm{b}$ ). The presence of abundant natural resources helps to absorb the excess greenhouse gases (GHGs) in the ambient atmosphere, thereby ensuring ecological sustainability. Therefore, the nations should have strict policies of preserving the natural resources, and their inhabitants and clearly defining the property rights for the use of public goods (Sinha et al., 2020a, b). These policy-level directives might be helpful in slightly achieving the objectives of the following three SDGs: (a) Goal 14: resilient aquatic life, (b) Goal 15: resilient life on land, and (c) Goal 12: accountability in resource utilization. SDGs' mentioned objectives can be achieved to some extent by protecting natural resources and helping them grow in abundance.

\section{Conclusion}

In the last decades, the European Union, especially the EU-5 countries, have applied strong environmental and energy regulations to control climate change. However, given the prevailing ecological situation in these nations, it is imperative to realign the existing policies or design a new policy framework. This might be necessary for EU-5 nations to attain SDGs' objectives by 2030, and hence, a multipronged SDG framework was necessary. By considering the case of the EU-5 economies, the present study is by far the first study in the literature to recommend a comprehensive SDG framework, while contemplating upon globalization and ageing to be major factors of sustainable development. Grounded on the study outcomes, this study's policy structure to accomplish the SDG objectives can be considered a new addition to the literature. This study has revealed a manner that principally ensures the objectives of SDG 7, SDG 13, and SDG 8 might be achieved, through plummeting ecological deprivation, endorsing energy innovation, and generating employment prospects through people-public-private partnership. In doing so, globalization can be deliberated as a policy instrument for accomplishing SDGs' objectives, while endorsing energy innovations and the policies proposed in this study have displayed an exploratory way to achieve it.

Along with the discussion on the policy agenda for the policymakers, it is also necessary to include the industry players in the framework in order to assure the sustainability of the policy framework. For sustaining the policy framework, the industrial sector needs to embark upon utilizing renewable energy solutions by replacing the traditional fossil-fuel solutions. This transformation should be carried out in a phase-wise manner, in collaboration with the government, so that their revenue stream remains unaffected. While carrying out this transformation, the industrial sector also needs to look into the aspect of job creation so that technological innovations do not replace physical labours. Without this aspect, the entire policy framework might not sustain. 
While discussing policy agenda, it necessitates evoking the fundamental assumptions, devoid of which the policy agenda might be ineffective. First, traded technologies should be ecologically responsive, as it can control negative environmental externalities, thereby moving a step towards the targets of SDG 13. Second, energy innovations should be undertaken in stages, as overnight substitution of fossil fuel solutions might weaken the growth trajectory. Third, an effective policy implementation for sustainable development requires residents' participation. It implies that people-public-private partnership should be invigorated, as this approach might support the policymakers to target the grassroots level.

\subsection{Directions for future research}

Conclusively, it is essential to note that the present study has been restricted to analyzing the evolutionary impact, whereas a study on globalized economies can be enriched by introducing the spatial impact. This is a limitation of the study, and therefore, it is to be remembered that the policy framework has not pondered upon the possibilities of spatial dependence in the data. However, this limitation can be addressed in the future by considering the trade relations among the EU-5 nations and by introducing the spatial dependence approach within a gravity model framework.

\section{Acknowledgement}

We are grateful to Prof. Dr Muhammad Shahbaz for his sincere support towards the successful completion of the study. We also extend our sincere gratitude to the Editor and anonymous reviewers, who have helped in upholding the quality of the work.

\section{References}

Aghion P., Hepburn C., Teytelboym A., Zenghelis D., 2014. Path Dependence, Innovation and the Economics of Climate Change. Policy Paper, Centre for Climate Change Economics and Policy. Grantham Research Institute on Climate Change and the Environment.

Álvarez A., Balsalobre, D., Cantos, J.M., Shahbaz, M., 2017. Energy innovations-GHG emissions nexus: fresh empirical evidence from OECD countries. Energy Policy, 101, 90100.

Auty, RM, 2001. Resource Abundance and Economic Development. Oxford University Press, Oxford.

Balsalobre D., Álvarez A.P., 2016. Economic growth and energy regulation in the environmental Kuznets curve. Environmental Science Pollution Research, 23(16), 1647816494.

Balsalobre D., Shahbaz M., Roubaud D., Farhani S., 2018. How economic growth, renewable electricity and natural resources contribute to $\mathrm{CO}_{2}$ emissions? Energy Policy, 113, 356-367.

Bravo-Ortega, C., De Gregorio, J., 2005. The relative richness of the poor? Natural resources, human capital, and economic growth. Natural Resources, Human Capital, and Economic Growth. Policy Research Working Paper 3484, World Bank.

Breusch, T.S., Pagan, A.R., 1979. A simple test for heteroscedasticity and random coefficient variation. Econometrica: Journal of the Econometric Society, 1287-1294.

Brunnschweiler, C.N., Bulte, E.H., 2008. The resource curse revisited and revised: A tale of paradoxes and red herrings. Journal of Environmental Economics and Management, 55(3), 248-264. 
Cantos, J.M., Balsalobre, D., 2013. Incidencia del gasto público en I+D+i energético sobre la corrección medioambiental en España. Estudios de economía aplicada, 31(1), 4-34.

Cavlovic, T., Baker, K.H., Berrens, R.P., Gawande, K., 2000. A meta-analysis of environmental Kuznets studies. Agriculture and Resource Economics Review, 29(1), 3242.

Chen, M., Sinha, A., Hu, K., Shah, M.I., 2021. Impact of technological innovation on energy efficiency in industry 4.0 era: Moderation of shadow economy in sustainable development. Technological Forecasting and Social Change, 164, 120521.

Chudik, A., Pesaran, MH, 2015. Common correlated effects estimation of heterogeneous dynamic panel data models with weakly exogenous regressors. Journal of Econometrics, 188(2), 393-420.

Corpataux, J., Crevoisier, O., Theurillat, T., 2009. The expansion of the finance industry and its impact on the economy: a territorial approach based on Swiss pension funds. Economic Geography, 85(3), 313-334.

COWI, 2008. Environment and Ageing: Final Report. European Commission DirectorateGeneral Environment.

Dalton, M., O’Neill, B.C., Prskawetz, A., Jiang, L., Pitkin, J., 2008. Population ageing and future carbon emissions in the United States. Energy Economics, 30(2), 642-675.

Danish, Baloch, M.A., Mahmood, N., Zhang, J.W., 2019. Effect of natural resources, renewable energy and economic development on $\mathrm{CO}_{2}$ emissions in BRICS countries. Science of the Total Environment, 678, 632-638.

Destek, M.A., Sinha, A., 2020. Renewable, non-renewable energy consumption, economic growth, trade openness and ecological footprint: Evidence from organisation for economic Co-operation and development countries. Journal of Cleaner Production, 242, 118537.

Dinda, S., 2004. Environmental Kuznets curve hypothesis: a survey. Ecological economics, 49(4), 431-455.

Dollar, D., Kraay, A., 2004. Trade, Growth, and Poverty. The Economic Journal, 114(493), F22-F49.

Dooley, J.J., 1998. Unintended consequences: energy R\&D in a deregulated market. Energy Policy, 26(7), 547-555.

Dreher, A., 2006. Does globalization affect growth? Evidence from a new index of globalization. Applied Economics, 38(6), 1091-1110.

Dumitrescu, E., Hurlin, C., 2012. Testing for granger non-causality in heterogeneous panels. Economic Modelling, 29(4), 1450-1460.

European Commission, 1990. Green Paper on the Urban Environment: Communication from the Commission to the Council and Parliament.

European Commission, 2014. Population ageing in Europe: Facts, implications and policies.

European Commission, 2018. The 2018 Ageing Report: Economic and Budgetary Projections for the EU Member States (2016-2070).

European Commission, 2020a. What is Horizon 2020?. Available at: https://ec.europa.eu/programmes/horizon2020/en

European Commission, 2020b. Environment and Trade and External Relations. Available at: https://ec.europa.eu/environment/integration/trade_en.htm

European Environmental Agency, 2020. The European environment — state and outlook 2020 (SOER 2020): Synthesis Report.

European Union (EU), 2014. Council of the European Union. 2030 Framework for Climate and Energy. Brussels: Council of the European Union; 2014.

Eurostat, 2019. Sustainable development in the European Union - Monitoring report on progress towards the SDGs in an EU context — 2019 edition. European Commission. 
Everaert, G., De Groote, T., 2016. Common correlated effects estimation of dynamic panels with cross-sectional dependence. Econometric Reviews, 35(3), 428-463.

Fan, Y., Liu, L.C., Wu, G., Wei, Y.M., 2006. Analyzing impact factors of $\mathrm{CO}_{2}$ emissions using the STIRPAT model. Environmental Impact Assessment Review, 26(4), 377-395.

Farzin, Y.H., Bond, C.A., 2006. Democracy and environmental quality. Journal of Development Economics, 81(1), 213-235.

Grossman, G., Krueger, E., 1991. Environmental Impacts of a North American Free Trade Agreement, NBER Working Paper No. 3914.

Gygli, S., Haelg, F., Potrafke, N., Sturm, J.E., 2019. The KOF globalization index-revisited. The Review of International Organizations, 14(3), 543-574.

Hamza, N., Gilroy, R., 2011. The challenge to UK energy policy: an ageing population perspective on energy saving measures and consumption. Energy Policy, 39(2), 782-789.

Hassan, J.K., Salim, R., 2015. Population ageing, income growth and $\mathrm{CO}_{2}$ emission: empirical evidence from high income OECD countries. Journal of Economic Studies, 42(1), 54-67.

Heijdra, B.J., Kooiman, J.P., Ligthart, J.E., 2006. Environmental quality, the macroeconomy, and intergenerational distribution. Resource and Energy Economics, 28(1), 74-105.

Jarque, C.M., Bera, A.K., 1987. A test for normality of observations and regression residuals. International Statistical Review, 55(2), 163-172.

Kahuthu, A., 2010. Economic growth and environmental degradation in a global context. Environment, Development and Sustainability, 8(1), 55-68.

Liddle, B., 2011. Consumption-driven environmental impact and age structure change in OECD countries: A cointegration-STIRPAT analysis. Demographic Research, 24(30), 749770.

List, J.A., Co, CY, 2000. The effect of environmental regulation on foreign direct investment. Journal of Environmental Economics and Management, 40(1), 1-20.

Menz, T., Welsch, H., 2012. Population aging and carbon emissions in OECD countries: Accounting for life-cycle and cohort effects. Energy Economics, 34(3), 842-849.

Menz, T., Welsch, H., 2010. Population ageing and environmental preferences in OECD countries: the case of air pollution. Ecological Economics, 69(12), 2582-2589.

O’Neill, B.C., Dalton, M., Fuchs, R., Jiang, L., Pachauri, S., Zigova, K., 2010. Global demographic trends and future carbon emissions. Proceedings of the National Academy of Sciences. Available at: www.pnas.org/cgi/doi/10.1073/pnas.1004581107

Panayotou, T., 1993. Empirical test and policy analysis of environmental degradation at different stages of economic development. Working Paper 238, Technology and Environment Programme, International Labour Office, Geneva.

Ramsey, J.B., 1969. Tests for specification errors in classical linear least-squares regression analysis. Journal of the Royal Statistical Society: Series B (Methodological), 31(2), 350371.

Roy, V., Schoenherr, T., Charan, P., 2018. The thematic landscape of literature in sustainable supply chain management (SSCM). International Journal of Operations \& Production Management, 38(4), 1091-1124.

Roy, V., Singh, S., 2017. Mapping the business focus in sustainable production and consumption literature: Review and research framework. Journal of Cleaner Production, 150, 224-236.

Shahbaz, M., Hye, Q.M.A., Tiwari, A.K., Leitão, N.C., 2013. Economic growth, energy consumption, financial development, international trade and $\mathrm{CO}_{2}$ emissions in Indonesia. Renewable and Sustainable Energy Reviews, 25, 109-121.

Shahbaz, M., Mallick, H., Mahalik, M.K., Loganathan, N., 2015. Does globalization impede environmental quality in India? Ecological Indicators, 52, 379-393. 
Shahbaz, M., Nasreen, S., Ahmed, K., Hammoudeh, S., 2017a. Trade openness-carbon emissions nexus: The importance of turning points of trade openness for country panels. Energy Economics, 61, 221-232.

Shahbaz, M., Bhattacharya, M., Ahmed, K., 2017b. $\mathrm{CO}_{2}$ emissions in Australia: economic and 10 non-economic drivers in the long-run. Applied Economics, 49(13), 1273-1286.

Shahbaz, M., Shahzad, S.J.H., Mahalik, M.K., 2018. Is Globalization Detrimental to $\mathrm{CO}_{2}$ Emissions in Japan? New Threshold Analysis. Environmental Modeling and Assessment, 23(5), 557-568.

Shahbaz, M., Balsalobre-Lorente, D., Sinha, A., 2019a. Foreign direct Investment-CO2 emissions nexus in Middle East and North African countries: Importance of biomass energy consumption. Journal of Cleaner Production, 217, 603-614.

Shahbaz, M., Destek, M.A., Okumus, I., Sinha, A., 2019b. An empirical note on comparison between resource abundance and resource dependence in resource abundant countries. Resources Policy, 60, 47-55.

Shahbaz, M., Sinha, A., 2019. Environmental Kuznets curve for $\mathrm{CO}_{2}$ emissions: a literature survey. Journal of Economic Studies, 46(1), 106-168.

Sharif, A., Baris-Tuzemen, O., Uzuner, G., Ozturk, I., Sinha, A., 2020a. Revisiting the role of renewable and non-renewable energy consumption on Turkey's ecological footprint: Evidence from Quantile ARDL approach. Sustainable Cities and Society, 57, 102138.

Sharif, A., Godil, D.I., Xu, B., Sinha, A., Khan, S.A.R., Jermsittiparsert, K., 2020b. Revisiting the role of tourism and globalization in environmental degradation in China: Fresh insights from the quantile ARDL approach. Journal of Cleaner Production, 272, 122906.

Shi, A., 2003. The impact of population pressure on global carbon dioxide emissions, 19761996: evidence from pooled cross-country data. Ecological Economics, 44(1), 29-42.

Sinha, A., Shah, M.I., Sengupta, T., Jiao, Z., 2020a. Analyzing technology-emissions association in Top-10 polluted MENA countries: How to ascertain sustainable development by quantile modeling approach. Journal of Environmental Management, 267, 110602.

Sinha, A., Sengupta, T., Alvarado, R., 2020b. Interplay between technological innovation and environmental quality: formulating the SDG policies for next 11 economies. Journal of Cleaner Production, 242, 118549.

Sinha, A., Shahbaz, M., Balsalobre, D., 2017. Exploring the relationship between energy usage segregation and environmental degradation in $\mathrm{N}-11$ countries. Journal of Cleaner Production, 168, 1217-1229.

Sinha, A., Shahbaz, M., Sengupta, T., 2018. Renewable Energy Policies and Contradictions in Causality: A case of Next 11 Countries. Journal of Cleaner Production, 197, 73-84.

Sinha, A., Gupta, M., Shahbaz, M., Sengupta, T., 2019. Impact of corruption in public sector on environmental quality: Implications for sustainability in BRICS and next 11 countries. Journal of Cleaner Production, 232, 1379-1393.

Tamazian, A., Chousa, J.P., Vadlamannati, C., 2009. Does Higher Economic and Financial Development Lead to Environmental Degradation: Evidence from BRIC Countries. Energy Policy, 37(1), 246-253.

Thalmann, P., 2004. The public acceptance of green taxes: 2 million voters express their opinion. Public Choice, 119(1-2), 179-217.

Tisdell, C.A., 2001. Globalization and Sustainability: Environmental Kuznets Curve and the WTO. Ecological Economics, 39(2), 185-196.

Theodore, L., 1983. The globalization of markets. Harvard Business Review, 61(3), 92-102.

Torras, M., Boyce, J., 1998. Income, inequality, and pollution: a reassessment of the Environmental Kuznets Curve. Ecological Economics, 25(2), 147-160.

United Nations Development Programme (UNDP) 2016. Human Development Report 2016. United Nations Development Programme. 
United Nations, 2018. The Sustainable Development Goals Report 2018. Available at. https://unstats.un.org/sdgs/report/2018.

United Nations Environment Programme (UNEP), 2020. Promoting resource efficiency: Regional Initiatives, Europe. Available at: https://www.unenvironment.org/regions/europe/regional-initiatives/promoting-resourceefficiency

Westerlund, J., Edgerton, D.L., 2008. A simple test for cointegration in dependent panels with structural breaks. Oxford Bulletin of Economics and Statistics, 70(5), 665-704.

Wooldridge, J.M., 2002. Inverse probability weighted M-estimators for sample selection, attrition, and stratification. Portuguese Economic Journal, 1(2), 117-139.

World Bank, 2018. World Development Indicators. Available at: https://data.worldbank.org/indicator

York, R., Rosa, E.A., Dietz, T., 2003. STIRPAT, IPAT and ImPACT: analytic tools for unpacking the driving forces of environmental impacts. Ecological Economics, 46(3), 351365.

Zafar, M.W., Shahbaz, M., Hou, F., Sinha, A., 2018. From Nonrenewable to Renewable Energy and Its Impact on Economic Growth: The role of Research \& Development Expenditures in Asia-Pacific Economic Cooperation Countries. Journal of Cleaner Production, 212, 11661178.

Zafar, M.W., Shahbaz, M., Sinha, A., Sengupta, T., Qin, Q., 2020. How renewable energy consumption contribute to environmental quality? The role of education in OECD countries. Journal of Cleaner Production, 268, 122-149. 